\title{
The Latin American and Caribbean Counter-Mobilization Against the UN Food Systems Summit: Magdalena Ackermann in Conversation with Saúl Vicente and Sofía Monsalve
}

\author{
Magdalena Ackermann $^{1}$ - Saúl Vicente ${ }^{2} \cdot$ Sofía Monsalve $^{3}$
}

Published online: 27 October 2021

(c) Society for International Development 2021

\begin{abstract}
What is the diagnosis of the main problems of the Latin American and Caribbean region, including the corporate capture of food systems? How did the regional counter-mobilization against the UN Food Systems Summit arise? What were the positions of the Latin American governments and regional organizations on the Summit? What is the common vision for overcoming corporate food systems? These are some of the questions that are discussed in this thought-provoking conversation with Sofía Monsalve and Saúl Vicente, in which they share their insights and experiences on the challenges of the Latin American region and the outcomes of the regional counter-mobilization against the UN Food Systems Summit.
\end{abstract}

Keywords Hunger $\cdot$ Malnutrition · Corporate capture of food systems $\cdot$ Food sovereignty $\cdot$ Agroecology $\cdot$ Agrarian reform

MA: What is the diagnosis of the main problems of the Latin American and Caribbean region, including the corporate capture of food systems? Could you give some specific examples?

$S M$ : In the regional counter-mobilization that was carried out prior to the global counter-mobilization ${ }^{1}$ in July, we had a very rich exchange where a diagnosis of the main problems within our region was made. Many elements were analyzed, but I will highlight here the instances where people see the greatest manifestations of corporate capture in food systems.

First, the high concentration of land and the extractivist model. Both these issues are very old and historical ones, and this is exposed by the reality of Latin America being one of the regions with the greatest inequality of land distribution in the world. Furthermore, the extractivist model continues to deprive people who live in the countryside of their territories, affecting particularly Indigenous Peoples and peasants.

Another issue that was also prominently raised was that of agrotoxics and how they intoxicate entire communities.

Magdalena Ackermann

mackermann@sidint.org

Society for International Development, Rome, Italy

2 International Indian Treaty Council, Oaxaca, Mexico

3 FIAN International, Heidelberg, Germany
The glyphosate spraying was particularly stressed in this regard. The industrial agricultural model, which is practiced on a fairly large scale particularly in the southern cone of the region, implies an intensive use of agrotoxics, thus severely impacting the health of these communities. Taking the example of Brazil alone, more than 600 new pesticides have been approved over the past two years. In other words, instead of a reduction in the use of agrotoxics, the region continues to experience an intensification of their use, which is very worrying.

Junk food is another major problem going to the account of corporate interests. I believe the region is a leader in public policy processes which are beginning to protect the population from junk food despite the fierce corporate resistance. There are different legislative initiatives, ranging from front-of-pack labelling to increasing taxes on sugary drinks, for example. In countries, such as Mexico and Brazil, citizen awareness on the importance of healthy eating became much stronger during the pandemic.

Finally, the last topic which came up in the diagnosis, and which I would like to particularly highlight, was the importance of democracy and the urgency to deepen it. Several national constituencies emphasized how their governments have an authoritarian bias and are ruling in favor of corporations while unfortunately dismantling public policy

\footnotetext{
${ }^{1}$ https://www.csm4cfs.org/thousands-mobilize-to-call-for-food-syste
} ms-that-empower-people-not-companies/ 
programmes which had been very important for advancing a vision of food sovereignty and agroecology.

MA: How did the regional counter-mobilization against the UN Food Systems Summit arise? Who convened it? Who participated and how was this regional counter-mobilization organized?

$S V$ : Precisely because of the initiatives launched by the Civil Society and Indigenous Peoples' Mechanism (CSM) ${ }^{2}$ for the relations with the Committee on World Food Security (CFS), Indigenous Peoples' organizations, small-scale food producers' organizations, consumers organizations and other organizations of those most affected by hunger, malnutrition and ecological destruction of Latin America and the Caribbean took up this call. They were deeply concerned with the food problems experienced in the Latin American region.

We reviewed the latest data from the world food security reports ${ }^{3}$ and, there are nearly 60 million people in Latin America who are undernourished. Latin America is in a moderate or severe situation of food insecurity. Furthermore, this situation happened through a $9 \%$ increase in moderate or severe food insecurity from 2019 to 2020.

Against these elements, social movements and organizations decided to participate in the counter-mobilization to transform corporate food systems. Many subregional or continental organizations participated in it, such as the Latin American Coordination of Peasant OrganizationsCLOC Vía Campesina, the Alliance for Food Sovereignty of Latin America, the Brazilian Forum for Food Sovereignty and Food and Nutritional Security (FBSSAN). Also, many national and regional organizations of agroecological territories in many countries-such as in Mexico, Colombia, Brazil, Nicaragua, Argentina, Ecuador.

Finally, many of the organizations that have been promoting the issue of food sovereignty decided to coordinate and convene a regional meeting to participate in this process by carrying out a counter-mobilization at the Latin American level.

The regional counter-mobilization was organized virtually, but without leaving aside the activities that we always carry out, for instance opening with the 'mistíca'. There were also cultural presentations, videos and, of course, the analysis based on the diagnosis that Sofía commented. It ended with a statement that included the diagnosis, the threats and the challenges, and the proposals that were raised. These were also brought to the global counter-summit in July.

$M A$ : What were the positions of the Latin American governments and regional organizations such as the Inter-American

2 https://www.csm4cfs.org/open-call-civil-society-indigenous-peopl es-engagement-respond-un-food-systems-summit/

${ }^{3}$ https://www.fao.org/3/cb4474en/cb4474en.pdf
Institute for Cooperation on Agriculture (IICA) regarding the UN Food Systems Summit (UNFSS)?

$S V$ : On an individual level, as Sofía has already commented, Latin American governments have had different positions, from those that have dismantled the entire food security system to those that have more progressive positions and are trying to change or transform food systems, particularly in light of the effects of the COVID-19 pandemic. In these contexts, food was underpinned as a fundamental element inducing diseases on people in Latin America and that the pandemic made clear these health pre-conditions made people more vulnerable to the infection by COVID- 19 .

The Latin American political context remains very diverse. Therefore, in our regional meeting, when sharing updates on the national dialogues, it was reported that in some places the organizations had a good relationship with their respective governments and had decided to participate in the national dialogues to strengthen the governments' positions.

In the case of Mexico, the National Movement of Producers and agroecology organizations decided to engage in the national dialogues to, particularly, strengthen a recently approved decree aiming to gradually prohibit the use of glyphosate in agriculture. Large corporations in Mexico undermined the prohibition of glyphosate by asking for this decree to be fixed. Therefore, the civil society organizations felt the need to participate in the national dialogues and reinforce their positions, support the decree, and move forward.

While in other countries, such as Brazil and others, the movements explained how the national dialogues were heavily biased. In those contexts, invitations for the national dialogues were very selective and were obviously addressed to those who shared the vision of agribusiness rather than the vision of the human right to food in the broader human rights framework. For this reason, movements in such countries had decided not to take part in the respective national dialogues and to convene other independent dialogues in their own countries.

On the other hand, but still as part of our regional process, preparing our declarations and for the different activities, what certainly caught our attention was the fact that regional organizations, such as IICA, had a view that was slightly closer to ours, although not entirely. It seemed interesting that the member countries of IICA's regional organization would attend the summit with a common position that had apparently been agreed upon in previous discussions and reflections. This common position had defined principles and key messages which the IICA member countries would take to the pre-summit in Rome. We learned about a 
document with 16 key messages ${ }^{4}$ on the fundamental role of agriculture in which they emphasized that farmers and food system workers are an essential and central network in food systems and that without agricultural production there would simply be no raw material to transform food.

The common position stated, therefore, that farmers should be duly represented, decisions should be based on science and agriculture should be part of the solution to the problems facing humanity.

It is important to note that within these 16 messages there were several fundamental themes. For example, one of them is related to the urgency of the transformation of the agri-food system. These messages highlight how food systems should build on the strengths that they have demonstrated and the contributions they have made. In addition, they expressed how food system workers and farmers are an essential link in food systems, and that their agriculture is fundamental to eradicating poverty, boosting rural development and protecting the environment. Finally, they also conveyed that, above all, multilateral systems should be given an increasingly active role in limiting trade distortion in these processes.

Those elements and messages are important to highlight, but the position also conveyed messages on consumer demand and nutritional aspects. They raised other messages on production strategies and environmental factors, pointing out the role of the Americas region in contributing to food and nutritional security in the world as the main food exporting region while also being the largest provider of ecosystem services and sources of biodiversity.

The messages also requested to include a proposal for productive inclusion and social protection. The document also impressed us because of its statement that the producers should be a fundamental part and participants in the process, debate and design of the strategies to be proposed.

Therefore, the role that the Latin American region was going to play seemed to be very important. Through these key messages, they decided to participate in the Pre-Summit held in July 2021. While I am not aware on how the positions evolved further in the process, it was an important element to take into account in our preparations.

$S M$ : I would add one additional nuance. This joint declaration or position mentioned by Saúl, which the Americas took to the Pre-Summit has the elements that Saúl highlights. However, it also offers an explicit defence of agribusiness throughout the region by saying that agro-exporting countries are very important for global food security.

It is a concept which was well articulated and that they want to defend. The position also contains another element

\footnotetext{
${ }_{4}$ https://iica.int/es/prensa/noticias/los-16-mensajes-claves-que-unier on-los-paises-de-las-americas-en-el-camino-hacia-la
}

of affinity with the Summit when it mentions that the role of science and innovation is very important for the challenges ahead and for sustainability. In other words, the position puts forward an agenda for agriculture 4.0, including the importance of data. I would argue that it is precisely on this that the position calls for international cooperation in order to strengthen these processes. It is therefore to have a nuanced view and stress that these contentious elements are also present in this joint positioning, highlighting significant areas of tension.

$M A$ : Is there a common vision for overcoming corporate food systems and, if yes, what does it entail? What is your analysis in terms of the continuation of regional organization and mobilization?

$S M$ : The political declaration of Latin America and the Caribbean ${ }^{5}$ that emerged from our regional process features a common diagnostic assessment, but it also points to a common vision. The most important element I would like to emphasize is that such a common vision calls for strengthening unity and alliances between our organizations, and different movements. The statement highlights that this counter-mobilization generated a positive effect in terms of a more consolidated convergence of organizations working on the issues of health and nutrition. But also, a convergence between the perspectives of consumers', climate justice and food sovereignty organizations. I would also stress the very strong presence of feminist organizations, across all these domains, as well. Therefore, the common vision is one of unity and of reinforcing those alliances.

I also believe that another key element is obviously the vision of food sovereignty. There was a huge commitment by all organizations to continue working in a practical way and politically position themselves in the frame of that vision. In this context, the issue of agrarian reform and the defence of territories was stated as playing a very important role in the region. As I mentioned at the beginning, Latin America is one of the regions with the greatest inequality in land distribution, resulting in deforestation and great ecological destruction. Thus, our vision has a strong call for a global, popular and agroecological agrarian reform. When the Chilean representative of the World March of Women presented the political declaration during the global countermobilization, this element had great resonance among the participants from other regions.

The last element I would highlight is the importance of strengthening the fight against ultra-processed food products and the struggle for public policies that discourage the

\footnotetext{
5 https://www.foodsystems4people.org/movilizacion-de-la-americalatina-para-desafiar-la-cumbre-de-sistemas-alimentarios-de-la-onu-yreclamar-la-soberania-de-los-pueblos-sobre-los-sistemas-alimentari os/?lang=es
} 
consumption of these products. This means putting an end to subsidies for the production of these products and strengthen the reconstruction of territorial ties to rescue biodiversity and the region's own traditional culinary practices.

Those would be the central points which I would highlight from the joint vision, besides the fact that there is also a clear structural and systemic understanding of how to advance food sovereignty and agroecology in the transformation of corporate food systems. In this respect, there was also a common understanding on the necessary fiscal and financial policies to make this vision a reality.

Regarding the last point on how we are going to continue, I would like to underline that the counter mobilization, as in other regions, revitalized the fight for food sovereignty and agroecology, with the latter being a key element of convergence between health and ecology. Therefore, the organizations are very enthusiastic and want to continue deepening the collective construction that took place within the framework of the counter-mobilization. And surely the issue of corporate capture is something that will keep us busy for a long time.

The next step for the continuation of this collective effort is probably the follow of the invitation made by the Continental Alliance for Food Sovereignty. Together with the global International Planning Committee for Food Sovereignty (IPC), the Alliance will be convening a large assembly, Nyéléni 3, where these efforts should be further developed. The vision of food sovereignty is therefore the key for a very strong regional convergence.

$S V$ : Perhaps another element that stood out from the countermobilization of the Latin American region is also the fight to guarantee the right to consultation and free and prior informed consent of peasants and Indigenous Peoples and communities. It is a central element because many of the plans and decisions that are taken to promote projects in the territories do not always apply the right to consultation with our Peoples. This is important to highlight since Convention 169 is practically signed by all the countries of the Latin
American region. It is therefore necessary to implement this legal instrument, which is now the law in all countries.

The other element I would add is that at the moment we must play on two courts. On one hand, we have spaces conquered by the movements of small-scale food producers, which are the CFS and the CSM. From there, we can take advantage of the conditions that allow us to be part of the multilateral system of the United Nations through the CFS and follow up and monitor the decisions that will be promoted based on the conclusions and results of the UN Food Systems Summit.

On the other hand, as Sofía has indicated, we need to go beyond the processes of counter-mobilization to strengthen the organization and the struggles of the social movements of small-scale food producers, such as our fight for food sovereignty. We need to redouble our efforts in the face of the threats to the peoples that continue the struggle for the transformation of corporate food systems. The attention needs to be focused on small-scale producers who, according to indicators, produce $70 \%$ of the world's food. Efforts need to continue to promote agroecological practices, transform food systems towards the approaches that have emerged from our counter-mobilization and to join alliances with other social movements that are fighting on other fundamental issues such as climate change, health or desertification. All these elements are interrelated with the problems we are experiencing in terms of land dispossession, health, and the effects of climate change.

Therefore, the call being made for the Nyéléni 3 Summit is an important one. In view of this, we need to strengthen our alliances with other movements, including those that will surely be present during the COP 26 on Climate Change and the COP15 on Biodiversity. It is fundamental to keep all these processes in mind.

Publisher's Note Springer Nature remains neutral with regard to jurisdictional claims in published maps and institutional affiliations. 